Caderno Seminal Digital

\title{
DO BELETRISMO À LINGUÍSTICA APLICADA: APONTAMENTOS PARA UMA HISTÓRIA DA INSERÇÃO DAS LETRAS NA PÓS-MODERNIDADE
}

\section{Luiz Fernando Dias Pita*}

O exercício da docência - em qualquer nível que esta se dê - leva-nos, invariavelmente, à reflexão sobre nossa prática: não só por visar-se aprimorar-se em seu exercício, mas também porque esta reflexão colabora para que elucidemos nossa inserção em determinada sociedade e a função que nela executamos. No que tangencia a área de Letras, esta reflexão faz-se ainda mais necessária, uma vez que, tendo esta área por objeto as manifestações da linguagem humana, e sendo a capacidade de expressão linguística um dos fatores constitutivos e distintivos da própria humanidade enquanto espécie animal, quaisquer transformações no conceito do ser humano interferem, por efeito reverso, diretamente nesta área.

Em suma, se o domínio da linguagem é um dos fatores que nos tornam humanos e nos capacitam a agir sobre o meio, saibamos que também o resultado dessas ações retroagem sobre nós, e, evidentemente, terão seus efeitos recaindo igualmente sobre a linguagem humana. Contudo,

Luiz Fernando Dias Pita tem Doutorado em Letras Clássicas (UFRJ, 2010) e Mestrado em Literaturas Hispânicas (UFF, 2000). É professor adjunto de Língua Latina na UERJ.

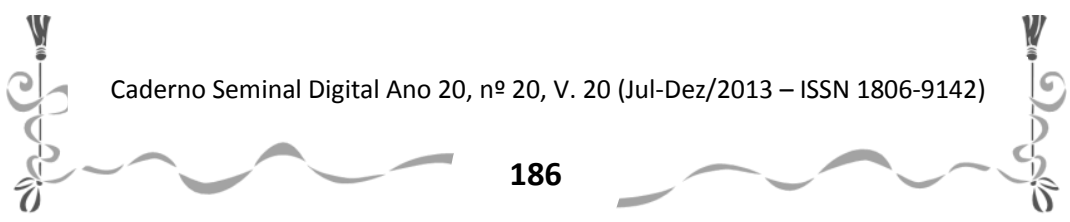


distintamente de outras áreas de conhecimento, a das Letras não nos parece ter a mesma capacidade de pronta reação a essas transformações sociais e da própria conceituação de ser humano. Analisar, ainda que sucintamente, a trajetória do efeito dessas transformações no âmbito dos estudos da linguagem e, por outro lado, a constituição de um ramo de conhecimento - a Linguística Aplicada - que se nos configura como o mais bem capacitado para acompanhar essas transformações, é a proposta deste trabalho.

Efetuaram-se, ao longo do século $X X$, inúmeras transformações na concepção do homem sobre si e sobre o universo que o circunda; além disso, modificaram-se também as relações humanas e as do homem com o meio ambiente. Também o universo tecnológico foi substancialmente modificado, causando uma revolução cujo impacto não pôde ainda ser medido com precisão. Mas, se desejássemos sintetizar em uma única palavra o efeito destas transformações sobre o ser humano, esta palavra seria "desagregação".

Desde as pesquisas de Freud sobre o "Inconsciente à Relatividade de Einstein"; da "Revolução Sexual à da Informática", todo o espectro de câmbios vividos pela Humanidade - ou, pelo menos, sua porção ocidental - no século XX teve como efeito colateral a derrocada da concepção linear e evolutiva da trajetória humana, tal como proclamada pelos positivistas do século XIX: em seu lugar, erige-se a noção de simples alteração dos conjuntos de valores sob os quais a

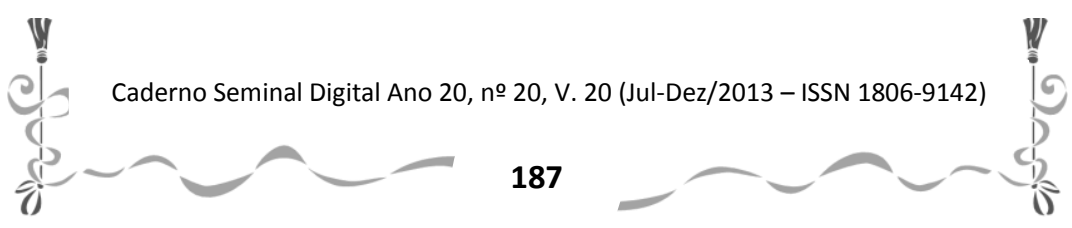


espécie se regeria. Assim, a desagregação da bem-acabada e sólida visão de um mundo homogeneizado sob a égide da civilização ocidental cede espaço a novas conceituações, tais como alteridade, polaridade, multiculturalismo, etc., sendo todas caracterizadas pela descentralização ideológica do universo cultural.

Paralelamente a estas transformações do conceito de cultura e civilização, percebe-se a avalanche provocada pelos avanços tecnológicos do século $X X$, avanços que têm seu ápice no desenvolvimento científico-industrial da Informática. As mudanças no cotidiano sempre resultaram das inovações tecnológicas; contudo, as mudanças que a Informática fez incorporar às atividades humanas alcançaram patamar inimaginado pelas gerações antecedentes. Basta-nos, para corroborá-lo, examinar a novela Paris no século $X X$ do francês Júlio Verne, considerado um dos pais da ficção científica. Neste texto, Verne descrevia a capital francesa do século XX funcionando graças a um emaranhado de máquinas baseadas na mecânica, na hidráulica e em diversas formas de propulsão pneumática; ou seja, não se podia sequer prever, mesmo em fins do século XIX, que todas as transformações tecnológicas futuras estariam baseadas na eletricidade, no eletromagnetismo e na eletrônica, enfim.

Quando atentamos para o uso que esses avanços tiveram na transformação do modo de produção capitalista ao longo do século $X X$, no qual se dá a passagem da sociedade

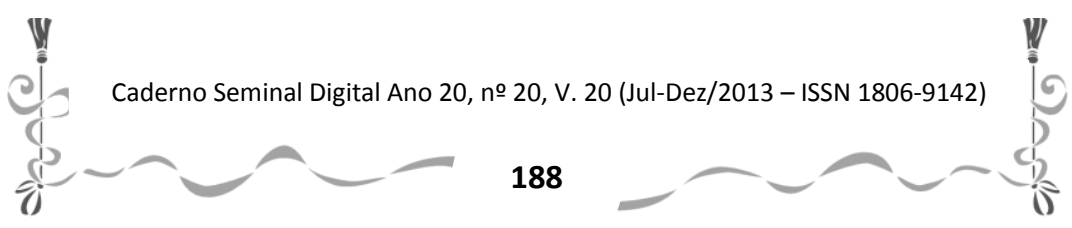


Caderno Seminal Digital

ats

industrial para a sociedade do conhecimento, verifica-se que a produção e gestão da tecnologia formaram uma simbiose com as forças do capital: estas oxigenam aquelas, enquanto aquelas propiciam o melhor desempenho e aplicação destas, acelerando o processo de globalização da Economia ${ }^{19}$.

Assim, o ser humano que alcança o terceiro milênio percebe-se vítima de uma situação dual: se as tecnologias uniformizam-se tomando a Informática como o vértice para a orientação dos rumos a seguir; as demais facetas do conhecimento humano são atingidas pela desagregação acima mencionada, o que engendra uma já denominada "crise de paradigmas" que se constitui em signo da Pós-Modernidade.

Tal dualidade, ao atingir os diversos setores do conhecimento, acaba por fazer com que - muitas vezes inconscientemente - diversos ramos das Ciências Humanas e Sociais tendam a assemelhar-se, em discurso ao menos, quando não em ideologia, ao discurso e à prática das áreas tecnológicas. Isso ocorre porque estas apresentam uma aparência de maior arcabouço: menos presas a ideologias e demonstrando maior eficácia na execução pragmática do que se proponha realizar - além da oxigenação de recursos proporcionada por sua relação simbiótica com o capital - a

${ }^{19}$ Dissemos "acelerando" uma vez que o processo de globalização da economia inicia-se, de fato, com as Grandes Navegações; sendo este impulso atual, calcado na inovação tecnológica, sua mais recente - e veemente - fase.

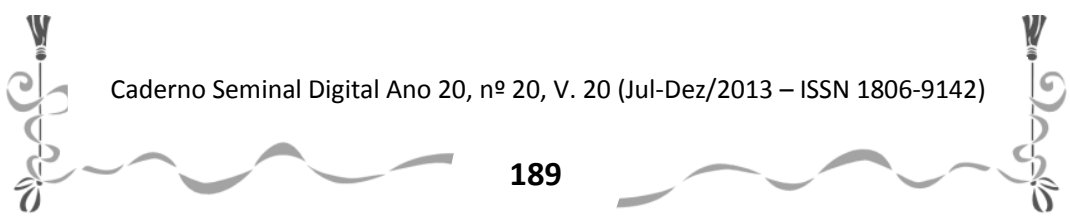


Caderno Seminal Digital

a

área tecnológica não deixa de representar um polo de atração magnética com que diversos segmentos das Humanidades têm se empenhado em flertar.

Evidentemente, seria leviandade afirmar que esta atração tenha se feito sem que tenha havido vozes discordantes e mesmo que existam setores em que a resistência ao processo tenha se constituído em bandeira de luta. Mas, no tocante à área de Letras, é claramente detectável que o rumo que alguns ramos deste setor de conhecimento tomaram estiveram, se não pré-estabelecidos, orientados pelo poder de atração que o desenvolvimento tecnológico tem demonstrado exercer.

Se antes afirmáramos terem as Ciências Humanas sofrido a perda de seus referenciais positivistas, um exame mais acurado sobre a área de Letras verificará a cisão que esta tem, desde fins do século XIX, enfrentado, e que se transformaram na nossa versão da "crise de paradigmas" mencionada acima. Tradicionalmente uma área erigida em favor do culto às Belas-Letras, e por essa razão direcionada prioritariamente às Artes e à Filologia; a carreira de Letras cindiu-se, visando dois objetivos distintos de conhecimento: o dos estudos literários e o dos estudos linguísticos; campo que, neste momento, importa-nos examinar mais amiúde.

Dissociando-se dos aspectos meramente historicistas da Filologia e buscando estudar todo o espectro de manifestações da linguagem verbal humana, a Linguística despontou ao longo

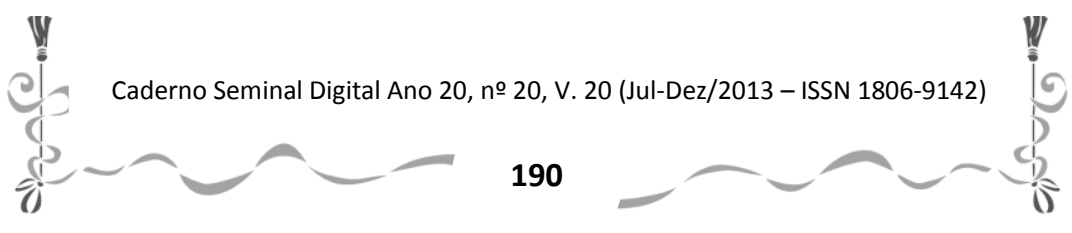


do século XX como a mais profunda revolução sofrida pela área de Letras, posto estabelecer novo pólo magnético para este âmbito do conhecimento. O crescimento - quantitativo e qualitativo - dos estudos realizados pelos que por seus parâmetros se nortearam fizeram com que a importância desta área no seio das Letras crescesse a ponto de absorver áreas outras - caso da Filologia mesma, outrora saber independente e hoje visto como subárea da Linguística - e de construir tantas outras vertentes de estudos que, hoje, opta-se, como estratégia para burlar o emaranhado teórico em que subjazem sob o nome de "Linguística", por usar-se o termo "Ciências da Linguagem", genérico a ponto de poder mesmo englobar a Semiótica.

Entretanto, uma rápida visualização das primeiras décadas da Linguística mostrará que a preocupação dos primeiros cientistas dessa área era eminentemente teórica e descritiva, como se percebe na afirmação abaixo, de Eugenio Coseriu (1980, p.9), em que se estabelecem tanto as distâncias da Linguística daquele período do historicismo quanto a proximidade com uma prática descritiva já exercida em séculos anteriores:

De fato, quando se afirma que a problemática linguística é a teoria ou a descrição, isto não implica a ausência total de temas históricos: eles são apenas menos importantes e, obviamente, com respeito ao problema principal da descrição, a história linguística se faz só de modo parcial e em função da própria descrição. Inversamente, quando

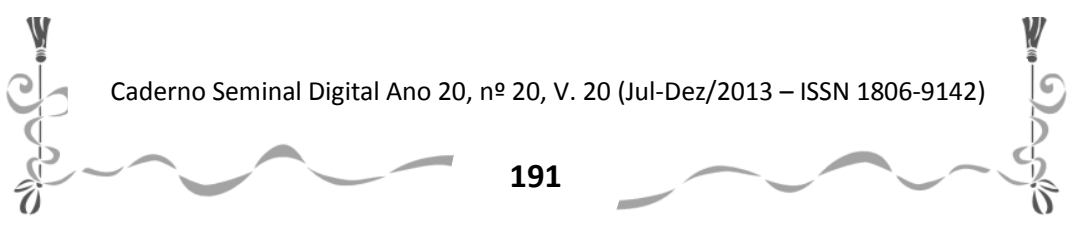




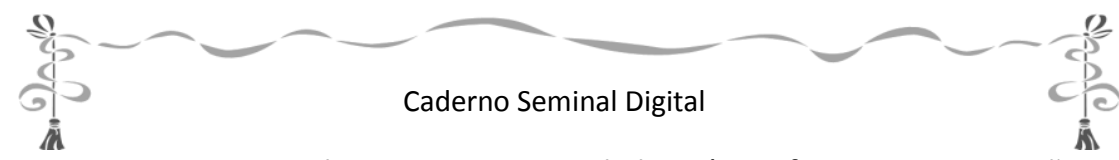

os objetivos essenciais da linguística foram a comparação e a história, a descrição certamente daí não desapareceu, mas passou, por assim dizer, ao segundo plano e, no caso foi feita em função da história. Assim, se no século XIX a linha principal do desenvolvimento da linguística passa pela linguística histórica, pela comparação linguística, pela história das línguas e pela gramática histórica, ao mesmo tempo se desenrola, debaixo desta mesma linha, a linguística teórica e descritiva, que continua a tradição do XVIII, tradição mais antiga e jamais desaparecida, [...] Deste ponto de vista, a linguística atual constitui um retorno, em primeiro plano, à linguística teórica e descritiva; de certo modo, ela retoma a problemática do século XVIII, porém em outras direções, impostas pela ampla experiência do século XIX, quando a linguística histórica se tinha a tornado a linguística por excelência. $(1980$, p.9)

Expondo que os rumos tomados pela Linguística geral representam antes o seguimento de uma tradição que o século XIX tornara secundária, Coseriu explicita também os motivos para que o surgimento de uma Linguística "aplicada" fosse não só viável, mas também desejável: em um momento da História humana em que a lógica de produção capitalista se inseria no meio acadêmico através das inúmeras agências de fomento que são criadas em diversos países nos primeiros decênios do século $X X$, cumpria transformar as pesquisas teóricas e descritivas: a), em resultados práticos para os órgãos de fomento dessas mesmas pesquisas e/ou, b), em subsídios concretos para outras áreas do conhecimento. Tal postura -

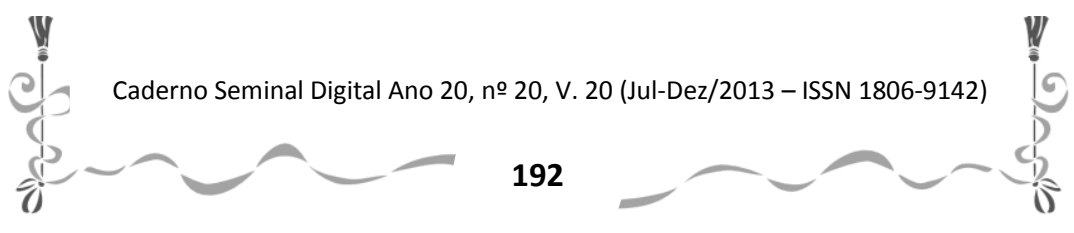


Caderno Seminal Digital

î.

que muitas vezes se apresenta de maneira crítica em diversos setores das Ciências Humanas - terminará por tornar mais aguda a necessidade de "aplicar" estes conhecimentos a alguma área de produção econômica.

Evidentemente, em se tratando de um período histórico de expansão de um capitalismo que se atrelava a interesses nacionais ${ }^{20}$, logo percebeu-se que a imagem e a cultura de um país são elementos representativos destes interesses, uma vez que podem gerar a simpatia de uma determinada população para com (os produtos manufaturados em) dado país; e que elas mesmas também são produtos passíveis de mercantilização. Tomando a dianteira desse processo, o governo francês cria, em 1921, o Centre de Recherches et d'Études pour la Diffusion du Français (CREDIF), instituição especializada no desenvolvimento de estratégias, políticas, técnicas e metodologias de ensino de francês para estrangeiros; e, em seguida, a Alliance Française, organização

20 Referimo-nos ao período entre-guerras (1918-1939), em que, mesmo tendo ocorrido a quebra da Bolsa de Nova York (1929), o capitalismo se expandia internacionalmente; ademais, a situação colonialista de países como Grã-Bretanha e França trazia a necessidade de implantar seus idiomas em suas próprias colônias algumas, caso da Índia, com uma tradição cultural muito mais antiga que a da metrópole.

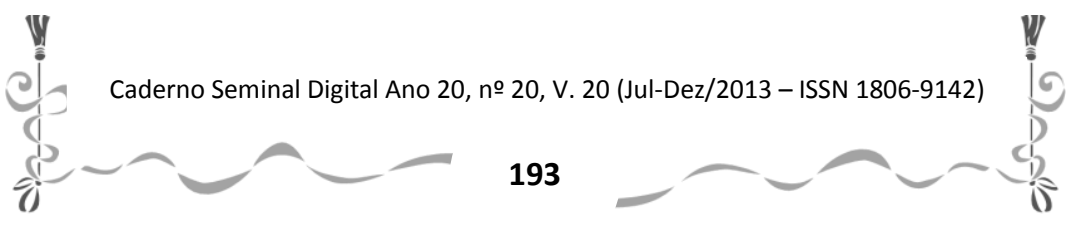


Caderno Seminal Digital

A

\section{Caderno Seminal Digital}

destinada a atuar, em países estrangeiros, como centro de divulgação da língua e cultura francesas ${ }^{21}$.

Percebe-se, pois, que a inserção da área de Letras caso que nos importa tratar, mas o mesmo é extensivo a todas as ciências humanas - no modo de produção capitalista do conhecimento surge a partir de uma necessidade das próprias forças do capital de estenderem-se para esse setor, em virtude de o ensino de línguas ter-se tornado ferramenta obrigatória para a manutenção de sua própria expansão. Importará, pois, verificar-se como, neste processo, atuou a Linguística Aplicada.

Constata-se que a mercantilização dos bens culturais e do ensino-aprendizagem de idiomas acaba por suscitar a necessidade de conjugar o conhecimento teórico e descritivo já formulado pelos linguistas a uma práxis que se reorganizava segundo paradigmas industriais. Analisemos, sucintissimamente, como se deu tal processo: a partir da mercantilização mencionada, a aprendizagem de idiomas passaria - a partir dos anos 30 - a ser vista não mais como uma fonte de aquisição de formas mais elevadas de cultura, mas como uma estratégia para colocar-se no mercado de trabalho e que, como tal, exigiria que a formação de um falante se desse do modo mais rápido, eficaz e de mais baixo custo possível.

21 Como sinal da globalização, hoje a Alliance Française visa a divulgação das culturas francófonas como um todo, uma vez que o potencial econômico de países como Bélgica e Canadá não podem ser desprezados.

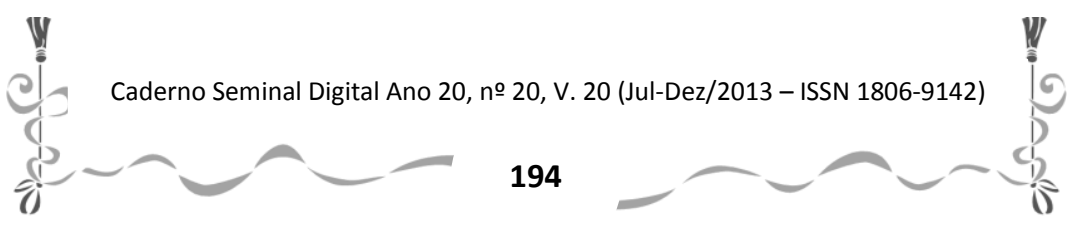


Caderno Seminal Digital

î

Estavam dadas as condições para que, no rol destas transformações, o ensino da língua assumisse um caráter mais técnico e fosse embasado sobre novas tecnologias. A partir da declaração de Claire Kramsch fica dedutível esta mudança de orientação e suas consequências até mesmo para o perfil do estudante de Letras:

Two developments in the modern history of foreign language study are making the relationship between applied linguists and language teachers into a discourse issue.

The first relates to developments in foregin language education. Due to demographic and social changes, the educates élite of industrializes countries has changed. The concept of a stable, consensual dicourse community composed of bellestristically inclined studentes has given way to the recognition of a diverse population of learners with changing needs who not only know little about the world beyond their national borders, but also very often cannot agree on any one definition of their national identity. (1995, p.44)

Ora, onde se buscar os embasamentos necessários para esta adequação senão nos conhecimentos oriundos da área de Letras? Dentre estes, cedo evidenciou-se que as pesquisas realizadas pelos linguistas eram as que mais subsídios poderiam fornecer ao empreendimento desejado.

A necessidade de novos processos de aquisição de segunda língua ficaram mais do que evidentes a partir da Segunda Guerra Mundial, em que, dadas as proporções do

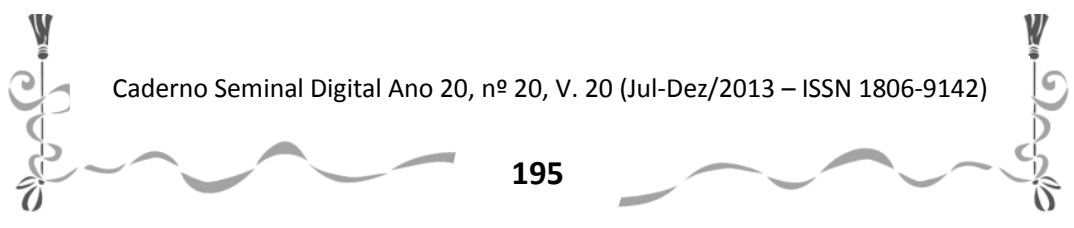


Caderno Seminal Digital

î.

conflito, um enorme contingente de tropas deveria aprender com rapidez e eficácia - a língua dos territórios que ocupassem; também os enormes esforços com espionagem e contra-espionagem, que exigiam um aprendizado ainda mais profundo, despertariam uma demanda ímpar - para um objetivo impensável - do desenvolvimento de novas técnicas de ensino e aprendizagem de idiomas ${ }^{22}$. Um exemplo disso foi o desenvolvimento, por parte do já mencionado CREDIF, de uma metodologia de ensino de francês que pudesse ser aplicada a um batalhão inteiro: ao fazê-lo, usou maciçamente os recursos da tecnologia, sendo este o embrião do modelo de ensino tecnicista, muito em voga até fins da década de $70^{23}$.

Constata-se, pois, existir-se uma "zona híbrida" - neste momento ainda indefinida - capaz de converter aqueles pressupostos teóricos e descritivos formulados pela Linguística em recursos de utilização prática e imediata para o ensino de línguas. Esta "zona híbrida" seria o espaço - ainda, e sempre de contornos indefinidos que uma nova vertente da Linguística, agora com o epíteto "Aplicada", viria a ocupar.

22 A importância do conhecimento de idiomas em operações militares revela-se patente quando analisados alguns dos eventos isolados ocorridos durante a atual ocupação norte-americana do Iraque; no Brasil, o Exército desenvolve programas de aprendizagem, por parte dos soldados que servem na Amazônia, das línguas indígenas da região.

${ }^{23}$ A metodologia desenvolvida pelo CREDIF é a usada no Brasil pela rede de cursos de inglês CCAA.

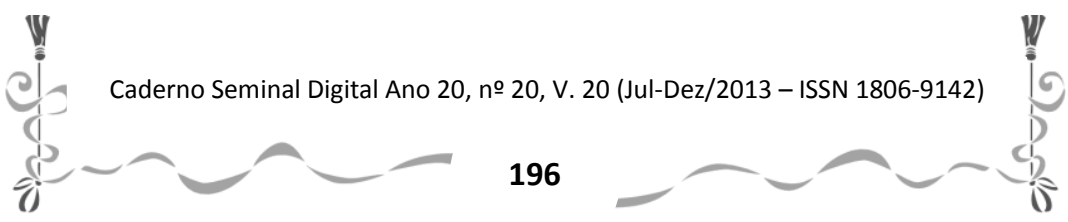


Caderno Seminal Digital

Antes de tratarmos mais acuradamente da diferenciação entre essas duas facetas da Linguística, convém esclarecer que, ao optarmos por privilegiar os aspectos econômicos pelos que a Academia é inserida no processo produtivo capitalista, não estamos: $a$ ), emitindo qualquer juízo de valor sobre os conhecimentos passíveis de mercantilização, e, b) colocando o capital à frente do processo de produção de conhecimento. Menos ainda queremos deixar implícito que o surgimento da Linguística Aplicada como ciência seja devido meramente a necessidades de mercado. Nesse sentido, queremos antes deixar cristalino que seu surgimento e desenvolvimento atendem também à necessidade epistemológica dos linguistas de testarem a validade, a universalidade e a aplicabilidade dos conhecimentos que formula(va)m. Reconhecemos ainda que diversos setores da Academia têm subsistido à margem dessa inserção, e que muito do que se produz(iu) em Letras e em Linguística o é/foi até mesmo em contra desse processo; contudo, não podemos negar que é em torno dessa injunção entre capital e conhecimento que os estudos acadêmicos - principalmente na contemporaneidade - se orientam.

Retomando o que antes disséramos sobre ser o surgimento da Linguística Aplicada precedido pela existência de uma "zona híbrida" formada pela intercessão entre os saberes produzidos pela Linguística e um ensino de línguas em reformulação, reiteremos que isto tão somente corrobora o

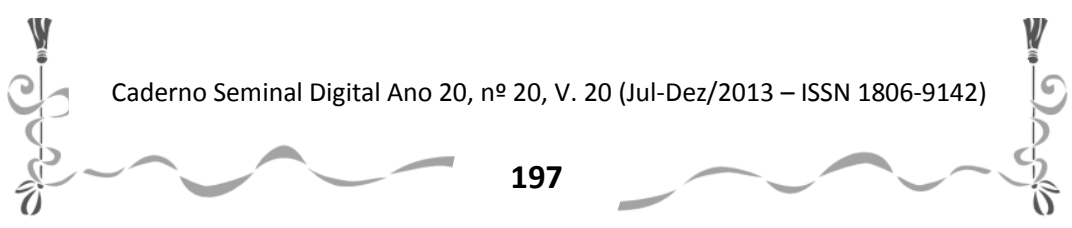


fato de que uma dada ciência só pode desenvolver-se havendo um campo epistemológico ao qual dedicar-se. No entanto, para que essa "zona híbrida" seja devidamente ocupada impõe-se que o ocupante legitime sua posse; o que sói fazer-se através da produção de discursos que lhe estabeleçam a identidade e atentem para a legitimidade mesma da reivindicação. É a partir deste momento que se inicia o processo de busca, por parte dos linguistas "aplicados", pela autonomia de sua práxis frente à Linguística. Esta busca, conforme veremos, compreenderá fases distintas.

O primeiro destes momentos seria aquele em que se dá a constatação da dita "zona híbrida" e se busca a ocupação do espaço, é aquele instante em que, conforme nos alerta Peter Strevens em seu artigo Applied Linguistics: an Overview (In: GRABE; KAPLAN, 1991, p.13-31), estudiosos da Universidade de Edimburgo e do Center for Applied Linguistics em Washington, DC, buscam, na segunda metade da década de 50, consolidar academicamente o projeto de expansão da língua inglesa no panorama internacional, por essa razão, confere-se à Linguística Aplicada uma dimensão exígua: a de meramente fornecer subsídios e estratégias para o ensino de idiomas, dimensão aliás que os pesquisadores em LA contemporâneos esforçam-se por superar. Nesse momento pode-se afirmar não haver um corpus teórico distintivo entre Linguística e a Linguística Aplicada, pois esta se serve diretamente daquela, razão pela que se afirmará que "The

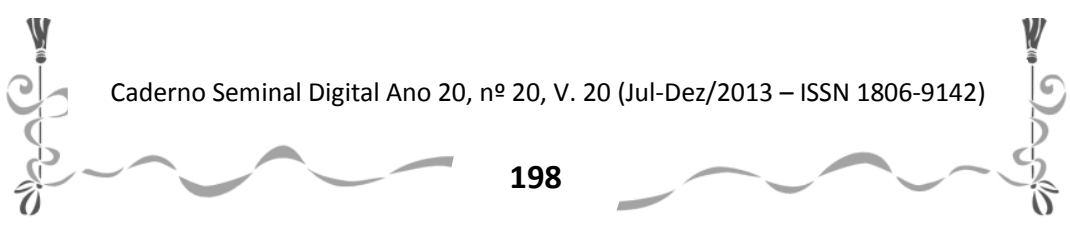


Caderno Seminal Digital

Applies Linguist is a consumer of theories [...] He is not a creator of theories.". A ênfase dada à afirmação demonstra o (ainda) reconhecimento de uma sujeição da Linguística Aplicada à disciplina-mãe; esta sujeição, contudo, seria algo de que linguistas aplicados logo tratariam de desfazer buscando a autonomia de sua disciplina. Outrossim, cedo estabelecer-seia a confusão entre a Linguística Aplicada e o ensino de línguas, e, de acordo com Bastos e Mattos (1993, p.11): "Mattoso Câmara, por exemplo, afirma que enquanto a Linguística descreve as estruturas das diversas línguas, a LA procura adequar essa descrição ao ensino".

$\mathrm{Na}$ busca de sua autonomia científica, os elementos particularizadores da identidade da LA como ciência seriam especialmente realçados, às vezes em detrimento mesmo dos elos que a unem à Linguística. Tal ação será fato ímpar e inusitado na história do desenvolvimento das ciências, pois, segundo Jânia Ramos:

... pode-se observar uma preocupação com a autonomia teórico-metodológica, o que em si é algo natural dado o espaço institucional alcançado. O que há de bastante curioso é que a autonomia é definida negativamente em relação à linguística teórica: quanto mais dissociada da linguística, mais autônoma seria a LA. A busca de autonomia, através da negação de pontos de contato com a teoria linguística, torna a LA atípica quando comparada a outras áreas de conhecimento definidas como aplicadas. (1993, p.33)

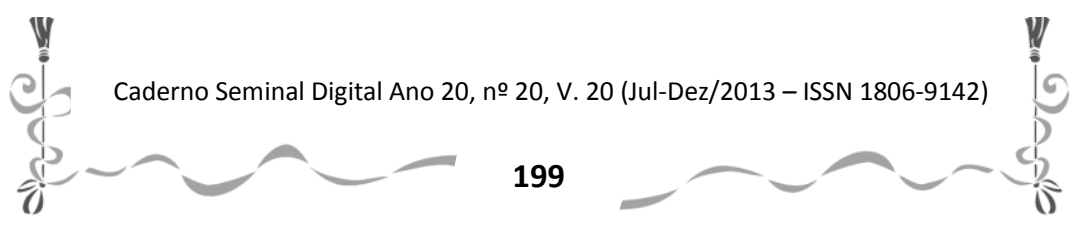


Caderno Seminal Digital

西

O que levou a uma situação bem analisada por William Grabe e Robert Kaplan, na sua introdução ao artigo "Applied Linguistics and Linguistics", escrito pelo primeiro:

Linguistics is the eponymic discipline of applied linguistics - an obvious statement perhaps, but the connection is too often minimized in applied-linguistics trainning programs. Two consequences arise as a result. First, linguistics tends to look on applied linguistics as a field without a theoretical foundaton; second, applied linguistics are often trained to distrust the seeming irrelevance of linguistic theory for their more practical concerns and needs. Both consequences are unfortunate. Applied linguistics, if anything, suffers from too much theoretical foundation rather than too little, drawing on theory from psychology, education, anthropology, and sociology, as well as linguistics. Applied linguistics, then, may choose to emphasize other research perspectives above current theoretical linguistics. The danger in this is the misperception that linguistics is treated too minimally by applied linguistics generally, and the more accurate perception that certain applied-linguistics training programs do not emphasize linguistic research sufficiently. The second consequence (related to the first) is that applied linguistics perceives theoretical linguistics as offering little in the way of practically useful knowledge. (1991, p.33)

O qual, além de apontar para as tensões do relacionamento entre as duas ciências-irmãs, demonstra ainda que a LA acabou por tornar-se fronteiriça também de outros campos do conhecimento - os mesmos com que a Linguística também já

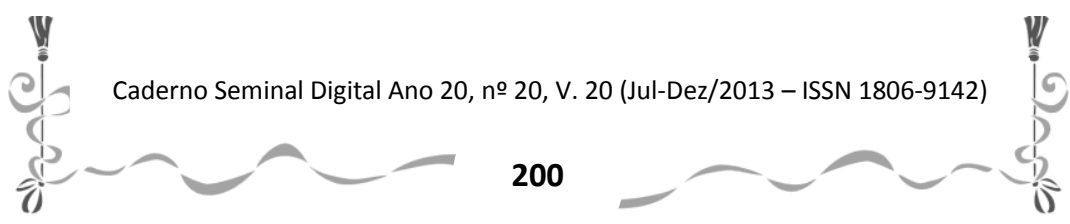


Caderno Seminal Digital

(1)

travara contatos -, recebendo destes tanta influência quanto a Linguística mesma. Fica evidente, pois, que o grande diferencial entre as duas ciências será sua posição quanto à práxis. Se a Linguística (Geral) valorizará a produção teórica e a investigação de caráter mais especulativo, à Linguística Aplicada interessarão aquelas informações que tiverem impacto na resolução de uma situação-problema, estas, como podem advir de procedimentos cujo estudo seja tarefa prioritária de outro campo do saber, serão determinantes na construção da multidisciplinaridade da Linguística Aplicada. Nesse aspecto entretanto, será suficiente retornarmos a palavra a Bastos e Mattos:

[...] a LA vai sempre - e mais - se constituindo como ciência de caráter multidisciplinar, ciência que acolhe contribuições de áreas da história, sociologia, da psicologia, etc. Dizemos que a LA usa elementos da Linguística e de outras ciências mas devemos entender que essas outras ciências são sempre e só aquelas cujos elementos são contemplados por algum dos ramos - ou desenvolvimentos - da própria Linguística dado exatamente o fato de que a LA tem como objeto elemento de linguagem.

Assim é que se recorrem a dados históricos, sociológicos, antropológicos, educacionais, estatísticos para se fazer um estudo em Linguística Aplicada, sempre pelo viés da linguagem enquanto fenômeno a ser abordado e da Linguística enquanto tratamento teórico da linguagem.

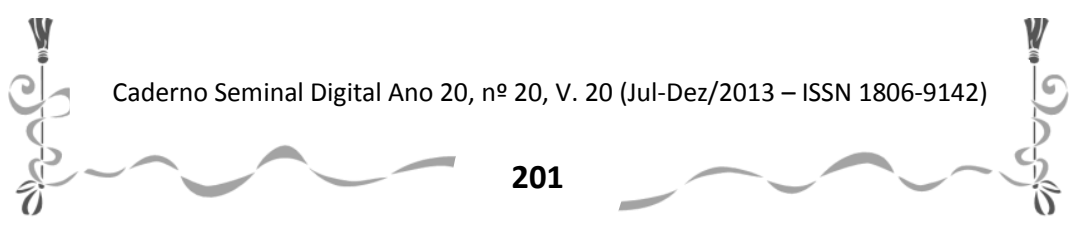




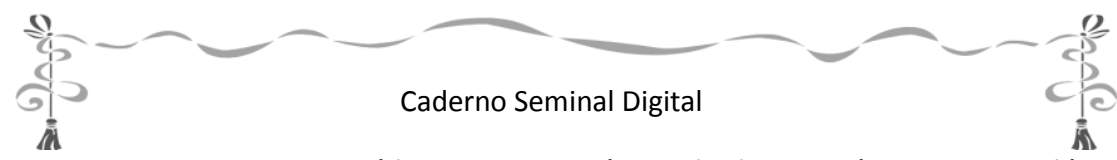

Se a LA é hoje a convergência de diversas áreas, isso se dá porque ela acompanha o desenvolvimento da Linguística na sua trajetória de empreender o fenômeno da Linguagem. (1993, p.17)

Tal fato apenas faz supor o esvanecimento das fronteiras "geográficas" entre as duas ciências e sua superposição enquanto saberes; fato que, simbolicamente, denuncia o artificialismo com que se buscava separá-las, pois que diferença, além da práxis, poderá haver entre duas áreas de conhecimento cujas fronteiras coincidem, que recebem as mesmas influências de outros campos de saber e que, por fim, repousam sobre estamentos compartilhados? Mas, além desse artificialismo, convém esclarecer que o esvanecimento das fronteiras do saber é uma das características da PósModernidade e um dos fatores expoentes da transição para a sociedade do conhecimento. Esta constatação fará com que se possa, hoje, assumir um tom conciliatório entre as duas ciências, e permitirá que Jânia Ramos possa definir concisamente o - mínimo - que as separa:

[...] a LA não se confunde com a linguística teórica, uma vez que se propõe a resolver problemas específicos e é movida por motivações distintas dessa última.

Entretanto, do ponto de vista epistemológico, a LA não constitui uma área independente da linguística. (In: BASTOS; MATTOS, 1993:38).

Se, pois, declarada a interdependência entre os dois tipos de conhecimento, constata-se que as fronteiras da

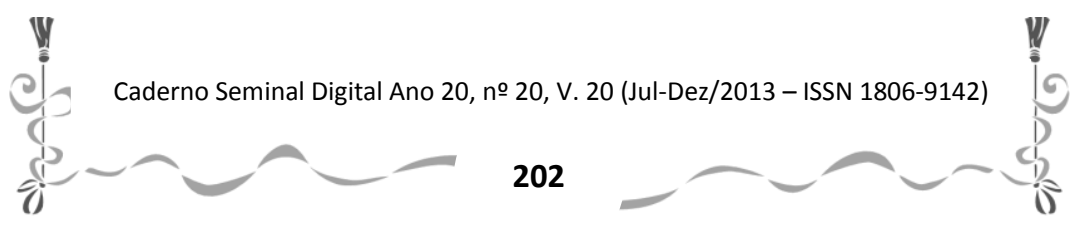


Caderno Seminal Digital

in

Linguística Aplicada coincidem com as da Linguística, destinando-se a primeira à resolução de problemas, convém por ora atentar ao questionamento levantado por Grabe e Kaplan, já na introdução de seu Introduction to Applied Linguistics:

What aspects of Linguistics can be applied; that is, what information from linguistics can be brought to bear on real-world language-based problems that applied linguistics presume to mediate? And what kind of problems can be solved through the mediation of applied linguistics? [...] The kinds of problems that applied linguists become involved with can largely be identified as communications problems, whether the communications is between individuals, either of equal or of unequal status, between communities of individuals, or between whole nations. $(1991$, p.6)

A imposição de um corte epistemológico que delimite também os caminhos da práxis da Linguística Aplicada necessidade subjacente na afirmação acima - acaba se resolvendo pela busca de possíveis soluções a problemas de comunicação - dentre os quais, na sociedade atual - a do ensino de idiomas. Ainda, este corte acaba também por criar uma disparidade entre o corpus teórico produzido pelos linguistas e aquele de fato utilizado pelos linguistas aplicados, tal como nos é evidenciado por Mackey:

When we examine the many theories of different schools and individuals we note that very few indeed have ever been applied. We also notice that those which have been

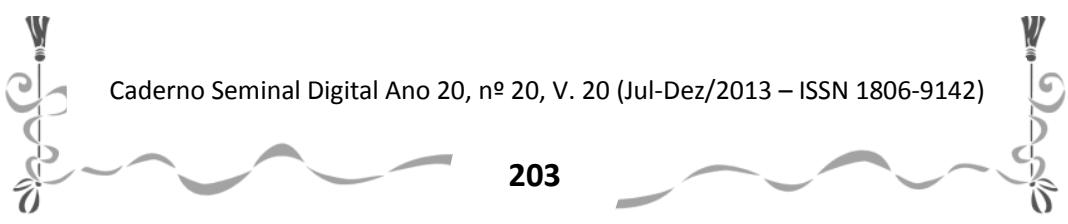




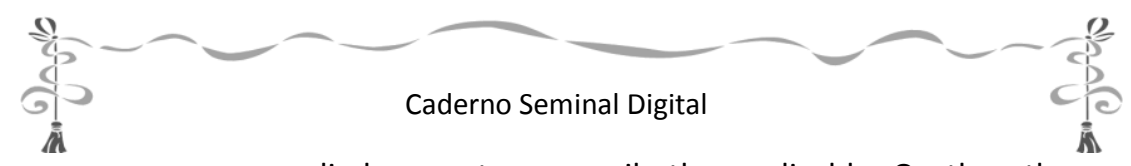

applied are not necessarily the applicable. On the other hand, the fact that a language theory has never been applied to language teaching does not mean that it cannot be. Some of the more ambitious and inclusive theories which seem to be the most relevant, have in fact never been applied. (1991, p.248)

Tal disparidade abre-nos passo a um questionamento - que não será desenvolvido em virtude das limitações deste trabalho - pode a Linguística Aplicada desenvolver teorias que Ihe sejam peculiares e diretamente afeitas à sua práxis? E já que de práxis se está tratando, e se até agora temos visto a Linguística Aplicada dirigida somente ao ensino de idiomas, quais seriam porventura os demais âmbitos de conhecimento aos quais a Linguística Aplicada pode oferecer seus préstimos? Esse segundo questionamento é-nos respondido no texto abaixo:

Questões a serem solucionadas pela LA podem ser, por exemplo, a) como se pode desenvolver um sistema escrito para uma língua com tradição puramente oral; b) como é possível aprender uma língua estrangeira rápida e corretamente; c) como se pode corrigir distúrbios da fala;

d) como se pode traduzir a Bíblia ou textos técnicos para "línguas exóticas"; e) como se pode elaborar um discurso de grande efeito. (SPILLNER, 1995, p.2-3).

Cremos que Spillner se detém apenas nos aspectos mais imediatos ou de maior porte, mas que dão suficiente amostragem das direções seguidas pela Linguística Aplicada. Fica implícito contudo, através dos itens $a, b$ e d, que questões

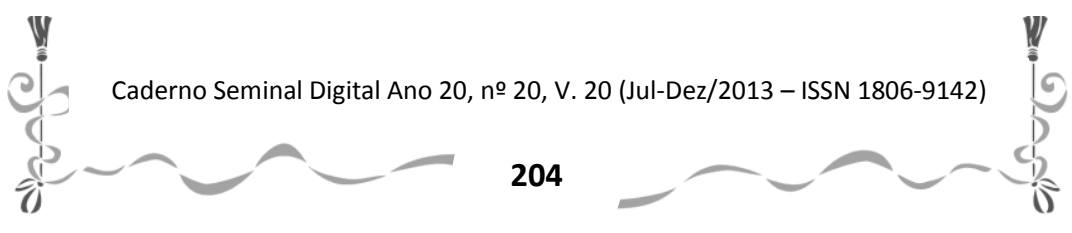


Caderno Seminal Digital

a

direta ou tangencialmente ligadas ao ensino de idiomas guardam relação imediata com a LA. Se isto não é sem precedente - afinal a gênese da própria LA está unida às reformulações do ensino de idiomas, como já tratamos reforça ainda o fato de que o ensino de idiomas se constitua, ainda hoje, no veio central das atividades da Linguística Aplicada. Retomando Spillner, o mesmo fará uma exposição inequívoca desta relação:

O ensino de línguas estrangeiras representa, no entanto, um campo prático muito importante da LA, tendo um papel central nas duas últimas décadas. Segundo a concepção abrangente de uma LA integrativa, a totalidade da área do ensino de línguas estrangeiras faz parte de seu objeto de estudos. Deve-se admitir, naturalmente, que as áreas da didática do ensino de literatura e do ensino da Landeskunde - com os quais obviamente existem relações linguísticas - têm sido exploradas na LA de forma muito menos intensiva do que aspectos comunicativos da aquisição de línguas estrangeiras, do que as dimensões de seleção, progressão e apresentação de elementos fonéticos, gramaticais, lexicais e pragmático-comunicativos. Não pairam dúvidas, contudo, sobre o fato de que a LA é responsável pela totalidade do ensino de línguas, considerando-se que ela tem como tarefa " $d$ 'améliorer cet enseignement en toutes circonstances et organisant l'enseignement compte tenu des découvertes scientifiques sur la nature du langage et sur la façon dont l'individu et la société l'assimilent et l'employent" (Corder, 1970:25). (1995, p.67)

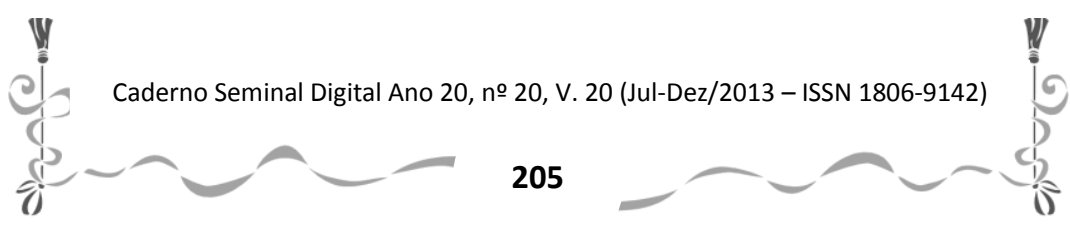


Caderno Seminal Digital

Não podemos todavia esquecer-nos que, ainda que responsável pela "totalidade do ensino de línguas" a LA exerce aí uma responsabilidade além da que Ihe seja destinada, por acabar recebendo atribuições que não lhe sejam pertinentes. Mesmo porque Spillner torna a nos chamar a atenção para o fato de que "com relação ao campo de aplicação "ensino de língua", os conhecimentos linguísticos e os métodos têm que ser combinados com os conhecimentos e métodos da psicologia da aprendizagem, da didática, dos estudos de meios técnicos, etc." (1995, p.3).

No tocante às combinações acima detectadas, importa fazer notar que, se nas últimas décadas a psicologia da aprendizagem e a didática fizeram avanços notáveis, estes não podem ser comparados à dimensão dos avanços ocorridos nos meios técnicos, onde ocorrerá uma (quase total) simbiose entre o ensino de idiomas e as chamadas Novas Tecnologias da Informação e Comunicação (TICs).

\section{REFERÊNCIAS BIBLIOGRÁFICAS:}

BASTOS, Lúcia K. X; MATTOS, Maria Augusta (eds.). Trabalhos em Linguística Aplicada 22. Campinas: UNICAMP/IEL, 1993.

COSERIU, Eugenio. Lições de Linguística Geral.Rio de Janeiro: Ao Livro Técnico, 1980.

GRABE, William ; KAPLAN, Robert (eds.). Introduction. In: Introduction to Applied Linguistics. Reading, Massachussets: AddisonWesley 1991. pp.1-9.

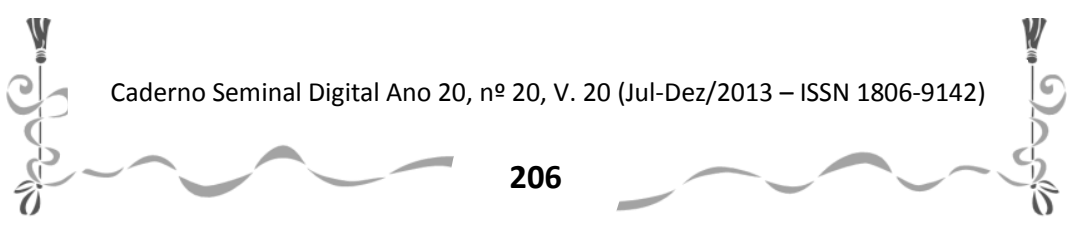


Caderno Seminal Digital

. Becoming an Applied Linguist. In: GRABE, William; KAPLAN,

Robert (eds.). Introduction to Applied Linguistics. Reading, Massachussets: Addison-Wesley, 1991. pp.281-301.

Applied Linguistics and Linguistics. In: GRABE, William; KAPLAN, Robert (eds.). Introduction to Applied Linguistics. Reading, Massachussets: Addison-Wesley, 1991. pp.33-58.

KRAMSCH, Claire. The Applied Linguist and Foreign Language Teacher: Can they talk to each other? In: COOK, Guy; SEIDLHOFER, Barbara (eds.). Principle \& Practice in Applied Linguistics: Studies in honour of H. G. Widdowson. Oxford: Oxford University Press, 1995. pp.43-56.

SPILLNER, Bernd. Linguística Aplicada. In: BAUSCH, Karl-Richard (ed.). Handbuch Fremdsprachenunterricht. Tübingen, Basel: Francke, 1995. pp.24-31.

STREVENS, Peter. Applied Linguistics: An overview. In: GRABE, William; KAPLAN, Robert (eds.). Introduction to Applied Linguistics. Reading, Massachussets: Addison-Wesley, 1991. pp.13-31.

Caderno Seminal Digital Ano 20, no 20, V. 20 (Jul-Dez/2013 - ISSN 1806-9142) 